\title{
Lymphovascular invasion is an important predictor of lymph node metastasis in endoscopically resected early gastric cancers
}

\author{
HYUNKI KIM ${ }^{1}$, JIE-HYUN KIM ${ }^{2}$, JUN CHUL PARK ${ }^{2}$, YONG CHAN LEE ${ }^{2}$, \\ SUNG HOON $\mathrm{NOH}^{3}$ and HOGUEN KIM ${ }^{1}$ \\ Departments of ${ }^{1}$ Pathology, ${ }^{2}$ Internal Medicine, Institute of Gastroenterology and ${ }^{3}$ Surgery, \\ Yonsei University College of Medicine, 120-752 Seoul, Republic of Korea
}

Received December 20, 2010; Accepted January 27, 2011

DOI: 10.3892/or.2011.1242

\begin{abstract}
With an increased incidence of early gastric cancer (EGC) and advances in endoscopic technologies, endoscopic resection (ER) has become an important treatment modality for EGC. Therefore, precise assessment of the risk of lymph node (LN) metastasis in ER specimens has become essential. The widely accepted criteria for ER have been mostly obtained from surgical data. This study was performed to evaluate the adequacy of these criteria and re-evaluate the predictive power of the criteria for LN metastasis. We evaluated a series of pathologic factors in ER specimens from 79 gastric cancer patients treated with endoscopic mucosal resection (7) or endoscopic submucosal dissection (72) and underwent subsequent surgical resection due to the potential risk of LN metastasis. Of the 79 patients, 10 patients (12.7\%) exhibited regional LN metastasis. Univariate analysis revealed that the presence of lymphovascular invasion (LVI) was significantly associated with $L N$ metastasis $(26 / 69,37.7$ vs. $9 / 10,90 \%, \mathrm{P}=0.004)$. The number of LVI was significantly higher in the LN metastasis group (1.1 \pm 2.3 vs. $7.7 \pm 8.4, \mathrm{P}<0.001)$. By multivariate analysis, the presence of LVI (odds ratio, 21.41; $\mathrm{P}=0.010$ ) and undifferentiated histology (odds ratio, 11.15; $\mathrm{P}=0.016$ ) were significantly correlated with LN metastasis. The presence of LVI, undifferentiated histology and the numbers of LVI were important risk factors for LN metastasis. Among these factors, the presence of LVI was the most important risk factor for LN metastasis in endoscopically resected early gastric cancer.
\end{abstract}

\section{Introduction}

With advances in diagnostic technologies and mass population screening, the proportion of early gastric cancer (EGC)

Correspondence to: Dr Hoguen Kim, Department of Pathology, Yonsei University College of Medicine, 250 Seongsanno, Seodaemun-gu, 120-752 Seoul, Republic of Korea

E-mail: hkyonsei@yuhs.ac

Key words: early gastric cancer, endoscopic resection, lymphovascular invasion, lymph node metastasis has rapidly and consistently increased, especially in Korea and Japan, over past decades (1-3). EGC have a favorable prognosis, with 5-year survival rates exceeding $90 \%$; however, the presence of lymph node (LN) metastasis significantly affects survival in these patients (84.6\% in the LN-positive group vs. $96.2 \%$ in the LN-negative group) $(1,4)$. The number of patients with EGC treated with endoscopic resection, either endoscopic mucosal resection (EMR) or endoscopic submucosal dissection (ESD), has rapidly increased in Korea (5). The new and refined ESD technique has accelerated this trend. Therefore, a precise prediction of LN metastasis in ER specimens is more important than ever. The more precise the prediction, the higher the chance for LN-negative EGC patients to be treated with stomach-preserving modalities such as endoscopic resection or limited surgical resection, and have a better quality of life.

The classic indication for EMR is a small ( $\leq 20 \mathrm{~mm}$ in size) differentiated intramucosal adenocarcinoma without ulceration (6). ESD with overcoming the limitation of the tumor size or location and an achievement of successful en bloc resection has extended the indications for EGC. The currently accepted indications for ESD for EGC are i) intramucosal differentiated adenocarcinoma without ulceration, regardless of size, ii) ulcerative intramucosal differentiated adenocarcinoma of $\leq 30 \mathrm{~mm}$ and iii) differentiated adenocarcinoma of $\leq 30 \mathrm{~mm}$ with minute submucosal invasion (SM1, $\leq 500 \mu \mathrm{m}$ ) (7). A small ( $\leq 20 \mathrm{~mm}$ in size) intramucosal undifferentiated adenocarcinoma without ulceration is a marginal indication for $\operatorname{ESD}(7,8)$. The presence of lymphovascular invasion (LVI) in the ER specimens is an indication for further surgical treatment, gastrectomy with LN dissection $(7,9)$. These criteria were obtained from studies that investigated pathological findings of gastrectomy specimens with $\mathrm{LN}$ dissection from a mostly Japanese dataset $(7,10,11)$. To validate these criteria and the adequacy of ER for EGC, several studies have reported the clinical outcome of EGCs treated with ER (5,12-15). Oda et al reported the clinical and surgical outcomes of 144 EGCs, which were treated with ER and underwent further surgical treatment due to the risk of $\mathrm{LN}$ metastasis. In the study, nine patients $(9 / 144,6.3 \%)$ had LN metastasis following surgery; (12) however, no study has investigated the pathologic param- 

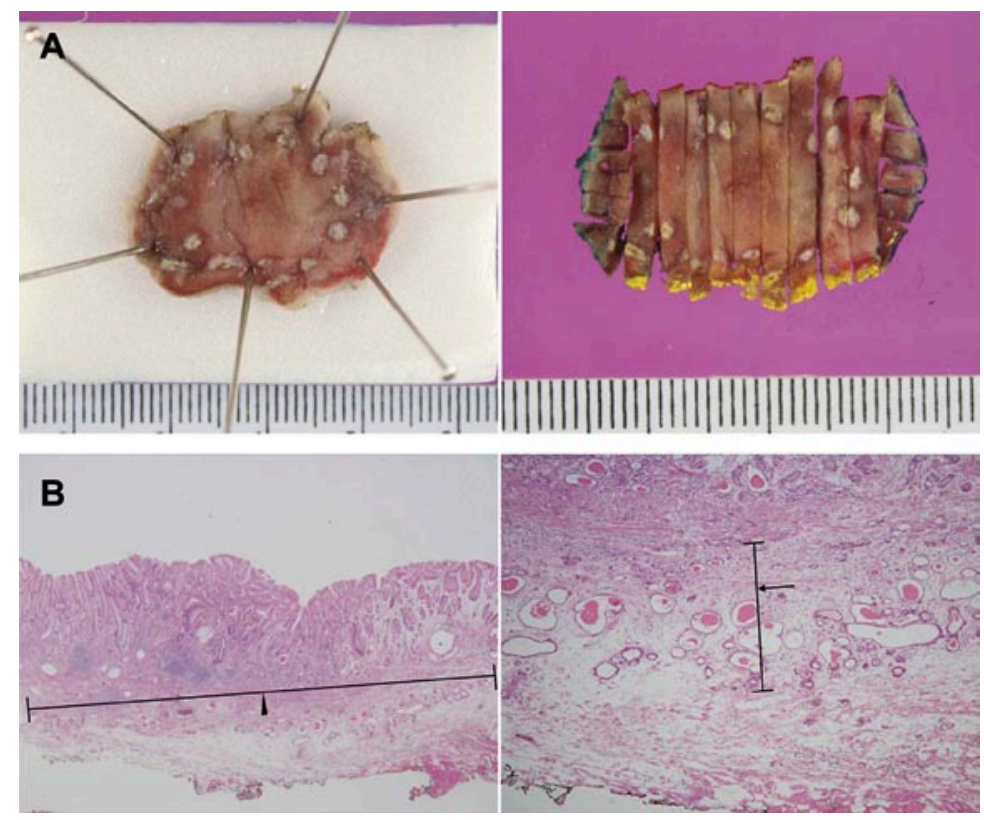

Figure 1. Representative figures of pathological evaluations of endoscopically resected specimens. (A) Endoscopic submucosal dissection specimens were pinned to a Styrofoam board and fixed in $10 \%$ formalin. After the lateral and vertical margins were marked with colored ink, the specimen was serially cut in 2-mm-wide sections. (B) The depth of submucosal invasion was measured as the distance from the lowest level of the muscularis mucosa to the end of the deepest point of invasion. The width of submucosal invasion was measured as the widest distance of the submucosal invasion. The arrow indicates the depth of submucosal invasion. The arrow head indicates the width of submucosal invasion.

eters in EGCs treated with ER, and underwent subsequent surgical treatment to assess the risk of LN metastasis. In this study, we evaluated a series of pathologic factors to assess their predictive power for LN metastasis in 79 gastric cancer patients who were treated with EMR (7) or ESD (72) and who underwent further gastrectomy with $\mathrm{LN}$ dissection due to the potential risk of LN metastasis.

\section{Materials and methods}

Patients. A total of 79 patients with gastric cancer treated by ER underwent further radical total/subtotal gastrectomy with $\mathrm{LN}$ dissection as a result of risks for $\mathrm{LN}$ metastasis at Severance Hospital, Yonsei University College of Medicine, Seoul, Korea, from January 2000 to October 2010. As determined by pathologic evaluation of the ER specimens, the potential risks for LN metastasis were i) the presence of LVI, ii) submucosal invasion of $>500 \mu \mathrm{m}$, iii) vertical resection margin-positive status and iv) undifferentiated carcinoma with ulceration, submucosal invasion or $>2 \mathrm{~cm}$ in size. Patients who had more than one of these risks underwent subsequent surgical resection and were included in this study. The patients had no clinical, ultrasonographic, or radiological evidence of LN or distant metastasis at the time of ER. Of the 79 patients, 77 patients underwent gastrectomy immediately (within 1 month) after ER, while the other two patients underwent gastrectomy after discovery of local recurrence or after suspicious identification of LN metastasis during follow-up endoscopic and radiological examination.

The following clinical factors were obtained from medical records: gender, age, tumor location, gross type, type of endoscopic resection (EMR or ESD), result of resection (en bloc or piecemeal) and type of gastrectomy. The gross type of the tumors was reclassified into three groups according to predominant morphology as follows: elevated, flat and depressed type.

The present study was performed in accordance with the guidelines issued by our institutional review board, which approved the retrospective study and waived the requirement for informed consent. All the patients provided informed consent for EMR or ESD after explanation of possible procedure-related risks, complications and alternative surgical options.

Pathological evaluation. ER specimens were pinned to a Styrofoam board and fixed in $10 \%$ formalin. After the lateral and the vertical resection margin of the specimens were marked with colored ink according to their orientation, the specimens were serially cut at a width of 2-3 mm and evaluated (Fig. 1A). All ER and surgical slides were obtained from the archives of the Department of Pathology, Yonsei University, Seoul, Korea. A series of pathological factors was reviewed and/or measured. These factors included the presence of ulceration, tumor size, histologic classification, invasion level (lamina propria, muscularis mucosa or submucosa), depth of submucosal invasion, width of submucosal invasion, state of lateral and vertical resection margin, presence of LVI and number of LVIs. Ulceration was defined histologically as a disruption of the muscularis mucosa with/without granulation tissue formation or submucosal fibrosis. The depth of submucosal invasion was defined as the distance from the lowest level of the muscularis mucosa (or surface of ulceration) to the end of the deepest tumor invasion. The width of submucosal invasion was defined as the widest distance of the submucosal invasive component (Fig. 1B). The area of submucosal invasion was calculated using an equation for half of the area of an ellipse $[1 / 2 \times \pi x$ major axis (half of the width of submucosal invasion) $\mathrm{x}$ minor axis (depth of submucosal invasion)]. For histologic classifica- 
Table I. Clinical characteristics of the 79 patients who underwent gastrectomy after endoscopic resection.

\begin{tabular}{lcc}
\hline Characteristic & No. of cases $(\%)(\mathrm{n}=79)$ \\
\hline Gender & $55(69.6)$ \\
Male & $24(30.4)$ \\
Female & $58.7 \pm 9.7(35-76)$ \\
Age (years) & & \\
Location & $12(15.2)$ \\
Cardia to UB & $14(17.7)$ \\
MB to LB & $53(67.1)$ \\
Angle to antrum & & \\
Endoscopic resection & 7 & $(8.9)$ \\
EMR & $72(91.1)$ \\
ESD & & \\
En bloc/Piecemeal & $61 \quad(77.2)$ \\
En bloc & $18(22.8)$ \\
Piecemeal & & \\
Surgery & $10(12.7)$ \\
RTG & $69(87.3)$ \\
RSTG & & $(12.7)$ \\
Residual tumor & $61(77.2)$ \\
No residual & 6 & $(7.6)$ \\
Mucosal only & $2.5)$ \\
Submucosal only & & \\
LNM with/without residual tumor & & \\
\hline
\end{tabular}

UB, upper body; MB, mid-body; EMR, endoscopic mucosal resection; ESD, endoscopic submucosal dissection; RTG, radical total gastrectomy; RSTG, radical subtotal gastrectomy; LNM, lymph node metastasis.

tion, the gastric carcinomas were classified according to the WHO classification (well, moderately, and poorly differentiated tubular adenocarcinomas and signet-ring cell carcinomas) and the Lauren classification (intestinal and diffuse type). Well and moderately differentiated tubular adenocarcinomas were classified as differentiated carcinomas, and poorly differentiated tubular adenocarcinomas and signet ring cell carcinomas were classified as undifferentiated carcinomas.

Statistical analysis. Statistical analysis was performed with SPSS for Windows (version 13.0; SPSS, Chicago, IL). To identify risk factors for LN metastasis, the data were subjected to univariate analysis using Fisher's exact test and the MannWhitney $\mathrm{U}$ test. To identify independent risk factors for LN metastasis, a multivariate binary logistic regression analysis (backward, stepwise) was applied using the following variables: size ( $\leq 3$ vs. $>3 \mathrm{~cm}$ ), ulceration (presence vs. absence), differentiation (differentiated vs. undifferentiated), Lauren classification (intestinal vs. diffuse), LVI (presence vs. absence), state of vertical margin (positive vs. negative), depth of submucosal invasion ( $\leq 500 \mathrm{vs.}>500 \mu \mathrm{m}$ ), width of submucosal invasion ( $\leq 6$ vs. $>6 \mathrm{~mm}$ ), and area of submucosal invasion ( $\left.\leq 3 \mathrm{vs} .>3 \mathrm{~mm}^{2}\right)$. LN metastasis rates were estimated with $95 \%$ confidence intervals, based on the exact binomial distribution. P-values $<0.05$ were considered statistically significant.

\section{Results}

Clinicopathologic characteristics. The 55 male and 24 female patients $(\mathrm{n}=79)$ who underwent gastrectomy had a mean age of $58.7 \pm 9.7$ years. Seven patients $(8.9 \%)$ underwent EMR, and the other patients $(72,91.1 \%)$ were treated by ESD. After surgical gastrectomy with LN dissection, $\mathrm{LN}$ metastasis was found in ten patients (12.7\%). Sixty-one patients (77.2\%) had no residual cancer, and eight patients had mucosal (6 patients, $7.6 \%$ ) or submucosal (2 patients, $2.5 \%$ ) residual cancer without $\mathrm{LN}$ metastasis. The clinical characteristics of these patients are summarized in Table I.

Based on the pathologic features of the ER specimens, the surgical indications for the 79 patients were i) the presence of
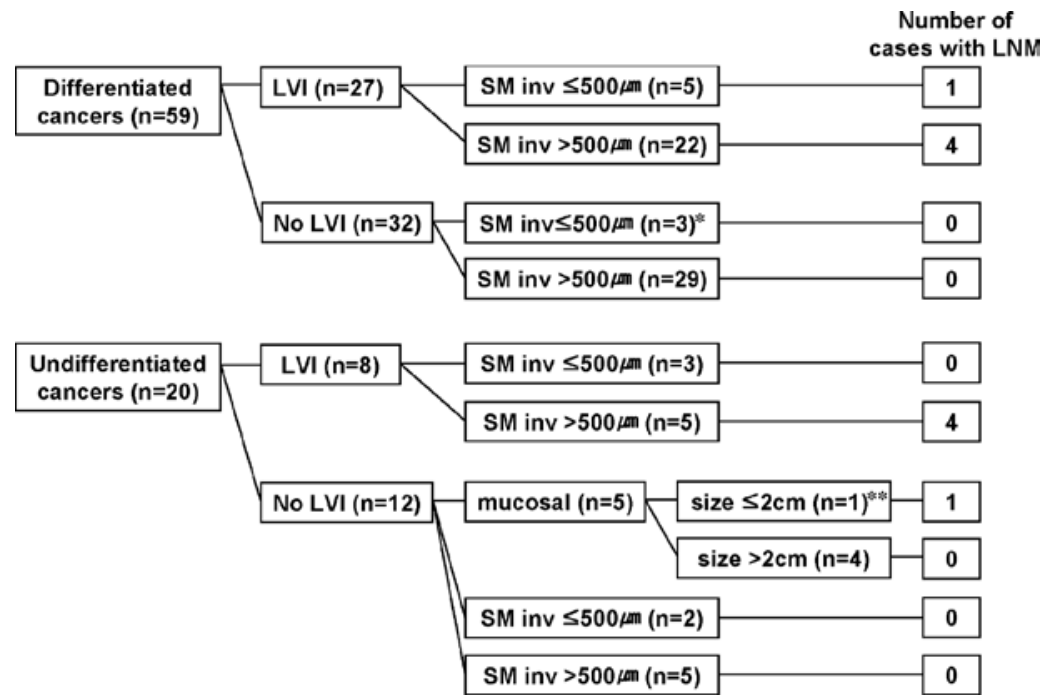

Figure 2. Flow chart of the surgical indications for the 79 patients treated with endoscopic resection according to the histologic differentiation, lymphovascular invasion, depth of submucosal invasion and status of LN metastasis after gastrectomy with LN dissection. *These 3 cases had submucosal invasion of $\leq 500 \mu \mathrm{m}$ in depth were positive for the vertical margin. ${ }^{* *}$ This mucosal undifferentiated cancer had an ulcer. LVI, lymphovascular invasion; SM inv, depth of submucosal invasion. 
Table II. Pathologic features of the 79 patients who underwent gastrectomy after endoscopic resection.

\begin{tabular}{|c|c|}
\hline Features & No. of cases $(\%)(n=79)$ \\
\hline Size $(\mathrm{mm})$ & $14.66 \pm 8.44$ \\
\hline \multicolumn{2}{|l|}{ Size } \\
\hline$\leq 3 \mathrm{~cm}$ & $76(96.2)$ \\
\hline$>3 \mathrm{~cm}$ & $3 \quad(3.8)$ \\
\hline \multicolumn{2}{|l|}{ Ulceration } \\
\hline Absent & $70(88.6)$ \\
\hline Present & $9(11.4)$ \\
\hline \multicolumn{2}{|l|}{ Gross type } \\
\hline Elevated (I or IIa) & $47(59.5)$ \\
\hline Flat (IIb) & $13(16.5)$ \\
\hline Depressed (IIc or III) & $19(24.1)$ \\
\hline \multicolumn{2}{|l|}{ Histology } \\
\hline WD & $33(41.8)$ \\
\hline MD & $26(32.9)$ \\
\hline PD, intestinal & $8(10.1)$ \\
\hline PD, diffuse or SRC & $12(15.2)$ \\
\hline \multicolumn{2}{|l|}{ Lauren classification } \\
\hline Intestinal & $67(84.8)$ \\
\hline Diffuse & $12(15.2)$ \\
\hline \multicolumn{2}{|l|}{ Invasion } \\
\hline Lamina propria & $6 \quad(7.6)$ \\
\hline Muscularis mucosa & $3 \quad(3.8)$ \\
\hline Submucosa & $70(88.6)$ \\
\hline \multicolumn{2}{|l|}{ Lymphovascular invasion } \\
\hline Absent & $44(55.7)$ \\
\hline Present & $35(44.3)$ \\
\hline No. of LVI $(n=35)$ & $1.9 \pm 4.2$ \\
\hline \multicolumn{2}{|l|}{ Resection margin } \\
\hline Negative & $36(45.6)$ \\
\hline Lateral positive & $8(10.1)$ \\
\hline Vertical positive & $35(44.3)$ \\
\hline \multicolumn{2}{|l|}{ SM invasion depth $(n=70)$} \\
\hline$\leq 500 \mu \mathrm{m}$ & $18(22.8)$ \\
\hline$>500 \mu \mathrm{m}$ & $61(77.2)$ \\
\hline SM invasion depth $(\mathrm{n}=70, \mathrm{~mm})$ & $1.44 \pm 0.99$ \\
\hline $\mathrm{SM}$ invasion width $(\mathrm{n}=70, \mathrm{~mm})$ & $5.98 \pm 3.98$ \\
\hline SM invasion area $\left(\mathrm{n}=70, \mathrm{~mm}^{2}\right)$ & $8.93 \pm 12.78$ \\
\hline
\end{tabular}

WD, well differentiated; MD, moderately differentiated; PD, poorly differentiated; SRC, signet ring cell carcinoma; LVI, lymphovascular invasion; SM, submucosal.

LVI invasion regardless of histologic type, invasion depth or resection margin state (35 cancers), ii) positive vertical margin without LVI regardless of histologic type and invasion depth $(22$ cancers), iii) submucosal invasion of $>500 \mu \mathrm{m}$ in depth without LVI and vertical margin involvement regardless of histologic

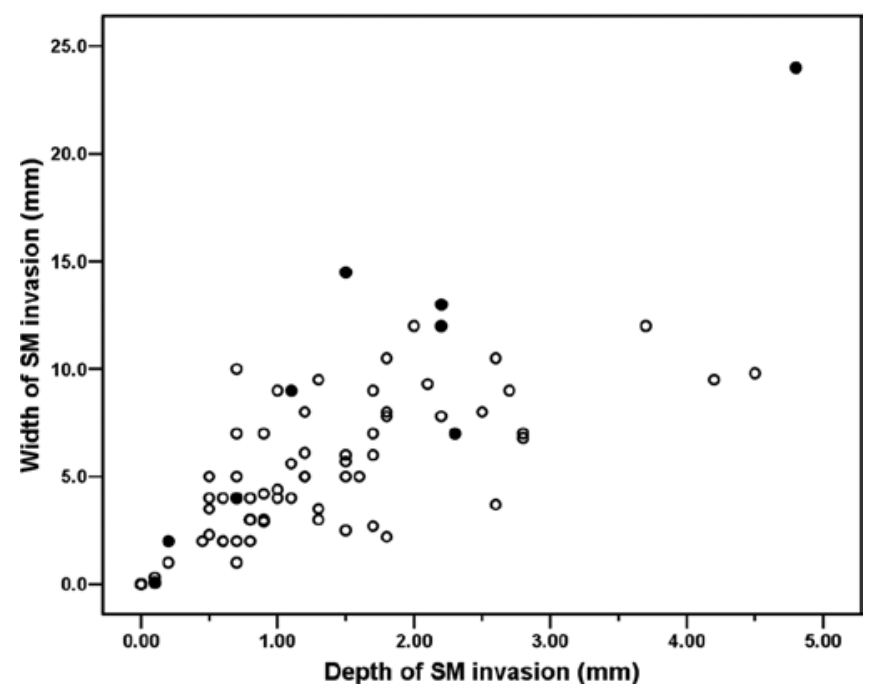

Figure 3. The relationship among the depth of submucosal invasion, width of submucosal invasion and LN metastasis. One intramucosal undifferentiated cancer with LN metastasis is not represented in this plot. Open circles show cases without LN metastasis, while closed circles indicate cases with LN metastasis.

type (15 cancers) and iv) undifferentiated cancers with submucosal invasion, $>2 \mathrm{~cm}$ in size or ulceration (7 cancers).

In terms of histologic differentiation, 59 of the 78 specimens (74.7\%) were differentiated cancers and 20 (25.3\%) were undifferentiated cancers. Of the 59 differentiated cancers, 27 cancers showed LVI regardless of submucosal invasion depth and resection margin state, and 32 cancers did not have LVI. Of these 32 cancers without LVI, 29 were submucosal cancers with a submucosal invasion depth of $>500 \mu \mathrm{m}$. Among the 29 submucosal cancers, 15 were also positive for vertical resection margin. The remaining three cancers, which did not display LVI and had submucosal invasion of $\leq 500 \mu \mathrm{m}$, were positive for vertical resection margin. Of the 20 undifferentiated cancers, eight showed LVI. Among the 12 cancers without LVI, the five mucosal cancers consisted of four cancers of $>2 \mathrm{~cm}$ in size and one ulcerative cancer in addition to the seven cancers, which showed submucosal invasion. The surgical indications for the 79 cases are illustrated in Fig. 2. The pathological features of the 79 ER specimens are summarized in Table II.

Among the 79 cancers, nine cancers were confined to the mucosa, while the other 70 cancers invaded the submucosa. In the 70 submucosal cancers, 61 (77.2\%) cases showed invasion of $>500 \mu \mathrm{m}$ in depth. The mean depth of submucosal invasion was $1.44 \pm 0.99 \mathrm{~mm}$, and the mean width of the submucosal invasion was $5.98 \pm 3.98 \mathrm{~mm}$. The relationship between invasion depth and width is shown in a scatter plot in Fig. 3.

Risk factors for LN metastasis. The rate of LN metastasis was $12.7 \%$ (10/79). The details of the ten patients with LN metastasis are summarized in Table III. Univariate analysis between the pathologic factors and surgical LN status revealed that the presence of LVI was significantly associated with LN metastasis $(26 / 69,37.7 \%$ in the node-negative group vs. $9 / 10,90 \%$ in the node-positive group; $\mathrm{P}=0.004)$. In the LVI-positive group $(\mathrm{n}=35)$, nine cases $(25 \%)$ showed LN metastasis after surgical 
Table III. Details of the 10 patients with LN metastasis.

\begin{tabular}{|c|c|c|c|c|c|c|c|c|c|c|c|c|c|}
\hline \multirow[b]{2}{*}{ Case } & \multirow[b]{2}{*}{$\begin{array}{l}\text { Gender/Age } \\
\text { (years) }\end{array}$} & \multirow[b]{2}{*}{ Location } & \multicolumn{9}{|c|}{ Endoscopic resection } & \multicolumn{2}{|c|}{ Gastrectomy } \\
\hline & & & Method & $\begin{array}{l}\text { Size } \\
(\mathrm{mm})\end{array}$ & $\begin{array}{l}\text { Gross } \\
\text { type }\end{array}$ & Ulcer & $\begin{array}{l}\text { Histology/ } \\
\text { Lauren }\end{array}$ & $\begin{array}{l}\text { SM depth } \\
\quad(\mathrm{mm})\end{array}$ & $\begin{array}{l}\text { SM width } \\
(\mathrm{mm})\end{array}$ & $\begin{array}{c}\text { Resection } \\
\text { margins }\end{array}$ & $\begin{array}{l}\text { No. of } \\
\text { LVI }\end{array}$ & $\begin{array}{l}\text { Residual } \\
\text { tumor }\end{array}$ & LNM \\
\hline 1 & $\mathrm{M} / 56$ & Antrum & ESD & 8 & 1lc & Absent & $\mathrm{PD} /$ intestinal & 0.8 & 3 & $\begin{array}{l}\text { Vertical } \\
\text { positive }\end{array}$ & 7 & Submucosal & $4 / 27$ \\
\hline 2 & $\mathrm{M} / 63$ & Antrum & EMR & 15 & IIa+llc & Absent & MD/intestinal & 0.1 & 0.1 & Free & 1 & No & $1 / 19$ \\
\hline 3 & $\mathrm{~F} / 69$ & Antrum & ESD & 30 & IIa+llc & Absent & WD/intestinal & 1.1 & 9 & Free & 17 & No & $1 / 23$ \\
\hline 4 & $\mathrm{~F} / 54$ & Antrum & ESD & 7 & III & Present & SRC/diffuse & 0.2 & 2 & $\begin{array}{l}\text { Lateral } \\
\text { positive }\end{array}$ & 10 & Subserosal & $24 / 32$ \\
\hline 5 & $\mathrm{M} / 40$ & Angle & ESD & 6 & IIa+III & Present & SRC/diffuse & 0 & 0 & Free & 0 & Mucosal & $1 / 28$ \\
\hline 6 & $\mathrm{M} / 63$ & Antrum & ESD & 8 & IIa+llc & Absent & MD/intestinal & 2.3 & 7 & $\begin{array}{l}\text { Vertical } \\
\text { positive }\end{array}$ & 1 & $\begin{array}{l}\text { Muscular } \\
\text { proper }\end{array}$ & $1 / 35$ \\
\hline 7 & $\mathrm{~F} / 65$ & MB & ESD & 18 & IIa+III & Present & $\mathrm{PD} /$ intestinal & 2.2 & 12 & Free & 3 & Subserosal & $3 / 42$ \\
\hline 8 & $\mathrm{M} / 49$ & UB & ESD & 20 & $11 \mathrm{~b}$ & Absent & WD/intestinal & 1.5 & 14.5 & Free & 10 & Mucosal & $18 / 54$ \\
\hline 9 & $\mathrm{M} / 59$ & LB & ESD & 22 & I & Absent & PD/intestinal & 2.2 & 13 & Free & 2 & Mucosal & $1 / 43$ \\
\hline 10 & $\mathrm{M} / 44$ & Antrum & ESD & 45 & IIa+llc & Absent & MD/intestinal & 4.8 & 24 & $\begin{array}{l}\text { Vertical } \\
\text { positive }\end{array}$ & 26 & Subserosal & $2 / 27$ \\
\hline
\end{tabular}

EMR, endoscopic mucosal resection; ESD, endoscopic submucosal dissection; WD, well differentiated; MD, moderately differentiated; PD, poorly differentiated; SRC, signet ring cell carcinoma; SM, submucosal; LVI, lymphovascular invasion; LNM, lymph node metastasis.

resection. Additionally, LVI was significantly more frequent in the LN metastasis group $(1.1 \pm 2.3$ in the node-negative group vs. $7.7 \pm 8.4$ in the node-positive group; $\mathrm{P}<0.001)$. The wellknown risk factors for $\mathrm{LN}$ metastasis, including a larger tumor size $(>3 \mathrm{~cm})$, submucosal invasion depth of $>500 \mu \mathrm{m}$, undifferentiated histologic type, and the presence of ulceration, showed no statistical significance by univariate analysis, probably due to the limited number of LN metastasis samples (Table IV).

Several possible risk factors for LN metastasis, including the presence of LVI, vertical margin status, tumor size, depth of submucosal invasion, width of submucosal invasion, area of submucosal invasion, histologic differentiation and Lauren type, were examined by multivariate logistic binary regression analysis. The presence of LVI (odds ratio, 21.41; $\mathrm{P}=0.010$ ) and undifferentiated histologic type (odds ratio, 11.15; $\mathrm{P}=0.016$ ) were significantly correlated with LN metastasis (Table V).

\section{Discussion}

We evaluated a series of pathologic features of ER specimens from 79 patients who were treated with ER and then underwent further surgical treatment due to potential LN metastasis. Of these specimens, LN metastasis was found in 10 patients $(12.7 \%)$. The reported $\mathrm{LN}$ metastasis rates of EGC range from 0.6 to $4.4 \%$ with an average of $3.2 \%$ for mucosal cancers and from 10 to $27 \%$ with an average of $19 \%$ for submucosal cancers (16). In the present study, the LN metastasis rates were $11.1 \%$ for mucosal cancers (1/9) and $12.9 \%$ for submucosainvasive cancers (9/70). Of the nine presumed submucosal cancer patients, only five patients were actually EGCs as the other four patients revealed residual cancers with more than submucosal invasion after surgical resection. Thus, the actual LN metastasis rate for submucosal cancers was
$7.6 \%(5 / 66)$, excluding the four cases that exhibited residual advanced cancer. The LN metastasis rate obtained for mucosal cancers in this study was significantly higher than the reported average rate $(3.2 \%)$ of mucosal cancers. This result supports the adequacy of the current criteria of ER for mucosal EGC; however, even though we selected patients at greater risk of LN metastasis and treated them according to the criteria, the actual LN metastasis rate (7.6\%) for submucosal cancers in this study was conversely lower than the reported average rate (19\%) of submucosal cancers based on surgical data (16). Despite the possibility of bias in this study from the limited number of LN-positive cases, these findings imply that more efforts should be made to refine the surgical criteria for patients with EGC who are treated with ER, especially ESD.

In the present study, the presence of LVI was the strongest predictor for LN metastasis with an odds ratio of 21.41 according to multivariate analysis. Of the ten cases with LN metastasis, LVI was observed in nine cases. The remaining LN-positive cancer, which lacked LVI, was an intramucosal signet ring cell carcinoma with ulceration. Of the 35 LVI-positive cases, nine cases $(21 \%)$ had LN metastasis. The differentiated cancers showed a trend of more frequent LVI; however, no statistically significant pathologic parameters were associated with LVI in this study. LVI is a well-known risk factor for LN metastasis (16). The pooled odds ratio from a meta-analysis of 13 studies is 10.88 (16). Gotoda et al reported that the detection rate of LVI in submucosal EGCs was 35.6\% (388/1091) and that the rate of LN-positive samples in the LVI-positive group was $41.2 \%$ (160/388) (17). Kang et al reported that rate of LN-positive samples in LVI-positive submucosal EGCs was $56.8 \%$ (25/44) (18). In comparison with these previous rates (41.2 and $56.8 \%$ ), our LN-positive rate $(21 \%, 9 / 35)$ in the LVI-positive group is much lower. This 
Table IV. Comparison of pathologic features of endoscopically resected gastric cancers according to $\mathrm{LN}$ metastasis.

\begin{tabular}{|c|c|c|c|}
\hline Factors & $\begin{array}{c}\text { No LN metastasis } \\
(\mathrm{n}=69)(\%)\end{array}$ & $\begin{array}{l}\mathrm{LN} \text { metastasis } \\
\quad(\mathrm{n}=10)\end{array}$ & P-value \\
\hline Size $(\mathrm{mm})$ & $14.19 \pm 7.74$ & $17.90 \pm 12.32$ & 0.496 \\
\hline Size & & & 0.076 \\
\hline$\leq 3 \mathrm{~cm}$ & $67(97.1)$ & 8 & \\
\hline$>3 \mathrm{~cm}$ & $2(2.9)$ & 2 & \\
\hline Resection & & & 1.000 \\
\hline En bloc & $53(76.8)$ & 8 & \\
\hline Piecemeal & $16(23.2)$ & 2 & \\
\hline Ulcer & & & 0.082 \\
\hline Absent & $63(91.3)$ & 7 & \\
\hline Present & $6 \quad(8.7)$ & 3 & \\
\hline \multicolumn{4}{|l|}{ Histologic } \\
\hline \multicolumn{4}{|l|}{ differentiation } \\
\hline Well to moderate & $54(78.3)$ & 5 & 0.112 \\
\hline Poor or SRC & $15(21.7)$ & 5 & \\
\hline \multicolumn{4}{|l|}{ Lauren type } \\
\hline Intestinal & $59(85.5)$ & 8 & 0.644 \\
\hline Diffuse & $10(14.5)$ & 2 & \\
\hline Vertical margin & & & 0.499 \\
\hline Negative & $37(53.6)$ & 7 & \\
\hline Positive & $32(46.4)$ & 3 & \\
\hline Invasion & & & 0.695 \\
\hline Mucosa & 8 (11.6) & 1 & \\
\hline $\mathrm{SM} 1(\leq 500 \mu \mathrm{m})$ & $7(10.1)$ & 2 & \\
\hline $\mathrm{SM} 2(>500 \mu \mathrm{m})$ & $54(78.3)$ & 7 & \\
\hline SM depth (mm) & $1.24 \pm 0.97$ & $1.52 \pm 1.46$ & 0.626 \\
\hline SM wide (mm) & $4.84 \pm 3.29$ & $8.46 \pm 7.65$ & 0.199 \\
\hline $\mathrm{SM}$ area $\left(\mathrm{mm}^{2}\right)$ & $6.55 \pm 7.91$ & $17.34 \pm 27.14$ & 0.312 \\
\hline $\begin{array}{l}\text { Lymphovascular } \\
\text { invasion }\end{array}$ & & & 0.004 \\
\hline Absent & $43(62.3)$ & 1 & \\
\hline Present & $26(37.7)$ & 9 & \\
\hline No. of LVI & $1.1 \pm 2.3$ & $7.7 \pm 8.4$ & $<0.001$ \\
\hline
\end{tabular}

SRC, signet ring cell carcinoma; SM, submucosal; LVI, lymphovascular invasion.

difference may stem from differences in the cutting method (2-3 mm thickness in ER specimens vs. 4-5 mm thickness in surgical specimens) or from the amount of effort to identify LVI in daily pathologic practice. The number of LVI in the samples was also significantly associated with LN metastasis.

With regard to histologic type, undifferentiated histology was also a strong predictor for LN metastasis with an odds ratio of 11.15 by multivariate analysis. In this study, 20 cases of undifferentiated carcinomas were treated with ER, probably due to the failure to accurately predict the submucosal invasion and/or the histologic type. Undifferentiated histology is also a well-known risk factor for LN metastasis of EGC
Table V. Multivariate analysis of risk factors for LN metastasis.

\begin{tabular}{lccc}
\hline Risk factors & Odds ratio & $\begin{array}{c}95 \% \text { Confidence } \\
\text { interval }\end{array}$ & P-value \\
\hline $\begin{array}{l}\text { Lymphovascular } \\
\text { invasion }\end{array}$ & & & \\
$\quad \begin{array}{l}\text { Present } \\
\text { Absent }\end{array}$ & 21.41 & $2.11-217.28$ & 0.010 \\
Differentiation & & & \\
$\quad$ Undifferentiated & 11.15 & $1.58-78.77$ & 0.016 \\
$\quad$ Differentiated & & & \\
\hline
\end{tabular}

with a pooled odds ratio of 2 (16). The rates of histological discrepancies of EGC between endoscopic forceps biopsy and surgical specimens and between endoscopic forceps biopsy and ER specimens were 17.5 and $25.6 \%$, respectively $(19,20)$. The discrepancies are important in the consideration of treatment modalities of EGC. Further study of these discrepancies using a large series of EGCs is necessary to evaluate the effects on the selection of ER candidates and to determine the outcomes of the endoscopic treatment.

The depth of submucosal invasion is a well-known risk factor for LN metastasis; (16) however, the depth of submucosal invasion was not significantly correlated with LN metastasis in this study. This lack of significance may stem from the limited number of the LN-positive cases in this study. Nevertheless, 34 EGCs, which invaded the submucosa by more than $500 \mu \mathrm{m}$ and did not have LVI, revealed no LN metastasis. One of the main purposes of this study was re-evaluation of the $500-\mu \mathrm{m}$ depth criterion, because the criterion originated from surgical specimens and the histological state of the submucosa between ER specimens and surgical specimens is different, including submucosal saline injection in EMR specimens, handling time prior to formalin fixation, and the stretching strength applied to the specimens in the formalin fixation (21). Despite the possibility of selection bias or casenumber limitation, our results indicate the necessity of further evaluation to refine the depth criterion using a larger series of ER specimens and the feasibility of extending the criterion in a subgroup of submucosal EGCs with a combination of additional parameters, including LVI; specific histologic type such as lymphoepithelioma-like carcinoma (medullary carcinoma); immunohistochemical results of biomarkers which have been reported as predictive markers for LN metastasis, such as matrix-metalloproteinase-9, Ki-67-labeling index and mucin phenotype; and genetic phenotype such as microsatellite instability (22-26).

The significance of submucosal width as a risk factor for LN metastasis has been reported for colorectal cancers $(27,28)$. To date, only one study has reported that a width of submucosal invasion that exceeds $6 \mathrm{~mm}$ is an independent risk factor for $\mathrm{LN}$ metastasis in submucosal invasive gastric cancers (odds ratio, 8.54; 95\% confidence interval, 2.24-41.2; $\mathrm{P}=0.0034$ ) (29). In the present study, although the submucosal invasion width was not a significant risk factor for LN metas- 
tasis, the scatter plot shows a trend that LN metastasis is more dependent on submucosal invasion width than on submucosal invasion depth (Fig. 3). To clarify the clinical significance of the width of submucosal invasion, further study focused on this parameter with a larger series of submucosal EGCs is necessary.

In the present study, other risk factors for LN metastasis, such as tumor size and presence of ulceration, were not statistically significant. Because these two parameters are more easily measured and recognized upon endoscopic examination than other pathologic parameters, these factors would be influenced more by a selection bias.

In conclusion, of 79 patients treated with ER and who underwent further surgical treatment due to the potential risk of $\mathrm{LN}$ metastasis, ten patients (12.7\%) exhibited LN metastasis. The presence of LVI, undifferentiated histology and number of LVI were significant risk factors for predicting LN metastasis. Among them, the presence of LVI was the most important risk factor for LN metastasis. Thus, pathologists should make every effort to find the LVI, if necessary, using additional methods, including step-serial sections or immunohistochemical study for lymphovascular makers such as D2-40, CD31 or CD34 and document not only the status of LVI but also the number of LVI in ER specimens on the pathology report.

\section{Acknowledgements}

The research was supported by the Converging Research Center Program through the Ministry of Education, Science, and Technology (2010K001115) and a faculty research grant from the Yonsei University College of Medicine for 2010 (6-2010-0142).

\section{References}

1. Park IS, Lee YC, Kim WH, Noh SH, Lee KS and Kim H: Clinicopathologic characteristics of early gastric cancer in Korea. Yonsei Med J 41: 607-614, 2000.

2. Kwon JH, Choi MG, Lee SW, et al: Trends of gastrointestinal diseases at a single institution in Korea over the past two decades. Gut Liver 3: 252-258, 2009.

3. Maehara Y, Kakeji Y, Oda S, Takahashi I, Akazawa K and Sugimachi K: Time trends of surgical treatment and the prognosis for Japanese patients with gastric cancer. $\mathrm{Br} \mathrm{J}$ Cancer 83: 986-991, 2000.

4. Soetikno R, Kaltenbach T, Yeh R and Gotoda T: Endoscopic mucosal resection for early cancers of the upper gastrointestinal tract. J Clin Oncol 23: 4490-4498, 2005.

5. Kim JJ, Lee JH, Jung HY, et al: EMR for early gastric cancer in Korea: a multicenter retrospective study. Gastrointest Endosc 66: 693-700, 2007.

6. Tsujitani S, Oka S, Saito $\mathrm{H}$, et al: Less invasive surgery for early gastric cancer based on the low probability of lymph node metastasis. Surgery 125: 148-154, 1999.

7. Gotoda T, Yanagisawa A, Sasako M, et al: Incidence of lymph node metastasis from early gastric cancer: estimation with a large number of cases at two large centers. Gastric Cancer 3 : 219-225, 2000.

8. Li C, Kim S, Lai JF, et al: Risk factors for lymph node metastasis in undifferentiated early gastric cancer. Ann Surg Oncol 15: 764-769, 2008.
9. Gotoda T: Endoscopic resection of early gastric cancer. Gastric Cancer 10: 1-11, 2007.

10. Gotoda T: Endoscopic resection of early gastric cancer: the Japanese perspective. Curr Opin Gastroenterol 22: 561-569, 2006.

11. Shimada Y: JGCA (The Japan Gastric Cancer Association). Gastric cancer treatment guidelines. Jpn J Clin Oncol 34: 58, 2004.

12. Oda I, Gotoda T, Sasako M, et al: Treatment strategy after noncurative endoscopic resection of early gastric cancer. Br J Surg 95: 1495-1500, 2008.

13. Ryu KW, Choi IJ, Doh YW, et al: Surgical indication for noncurative endoscopic resection in early gastric cancer. Ann Surg Oncol 14: 3428-3434, 2007.

14. Nagano H, Ohyama S, Fukunaga T, et al: Indications for gastrectomy after incomplete EMR for early gastric cancer. Gastric Cancer 8: 149-154, 2005.

15. Song KY, Hyung WJ, Kim HH, et al: Is gastrectomy mandatory for all residual or recurrent gastric cancer following endoscopic resection? A large-scale Korean multi-center study. J Surg Oncol 98: 6-10, 2008

16. Kwee RM and Kwee TC: Predicting lymph node status in early gastric cancer. Gastric Cancer 11: 134-148, 2008.

17. Gotoda T, Sasako M, Ono H, Katai H, Sano T and Shimoda T: Evaluation of the necessity for gastrectomy with lymph node dissection for patients with submucosal invasive gastric cancer. Br J Surg 88: 444-449, 2001.

18. Kang HJ, Kim DH, Jeon TY, et al: Lymph node metastasis from intestinal-type early gastric cancer: experience in a single institution and reassessment of the extended criteria for endoscopic submucosal dissection. Gastrointest Endosc 72: 508-515, 2010.

19. Matsubara Y, Yanai H, Ishiguro K, et al: Clinical interpretation of the histological typing of gastric cancer using endoscopic forceps biopsy. Hepatogastroenterology 51: 285-288, 2004.

20. Lee CK, Chung IK, Lee SH, et al: Is endoscopic forceps biopsy enough for a definitive diagnosis of gastric epithelial neoplasia? J Gastroenterol Hepatol 25: 1507-1513, 2010.

21. Cho JY, Kim YS, Jung IS, et al: Controversy concerning the cut-off value for depth of submucosal invasion after endoscopic mucosal resection of early gastric cancer. Endoscopy 38: 429-430; author reply 430, 2006.

22. Otsuji E, Kuriu Y, Ichikawa D, et al: Clinicopathologic and prognostic characterization of poorly differentiated medullarytype gastric adenocarcinoma. World J Surg 28: 862-865, 2004.

23. Kabashima A, Maehara Y, Kakeji Y, Baba H, Koga T and Sugimachi K: Clinicopathological features and overexpression of matrix metalloproteinases in intramucosal gastric carcinoma with lymph node metastasis. Clin Cancer Res 6: 3581-3584, 2000.

24. Maeda K, Chung YS, Onoda N, et al: Association of tumor cell proliferation with lymph node metastasis in early gastric cancer. Oncology 53: 1-5, 1996.

25. Nakamoto J, Torisu R, Aoki R, et al: Clinicopathological evaluation of biological behavior of submucosal invasive gastric carcinomas: relationship among lymph node metastasis, mucin phenotype and proliferative activity. J Med Invest 54: 99-108, 2007.

26. Lee HS, Choi SI, Lee HK, et al: Distinct clinical features and outcomes of gastric cancers with microsatellite instability. Mod Pathol 15: 632-640, 2002.

27. Masaki T, Sugiyama M, Matsuoka H, et al: Clinical utility of grading criteria for submucosal invasion in the prognosis of T1 colorectal carcinomas. J Gastroenterol 38: 37-44, 2003.

28. Ueno H, Mochizuki H, Hashiguchi Y, et al: Risk factors for an adverse outcome in early invasive colorectal carcinoma. Gastroenterology 127: 385-394, 2004.

29. Sanomura Y, Oka S, Tanaka S, et al: Predicting the absence of lymph node metastasis of submucosal invasive gastric cancer: expansion of the criteria for curative endoscopic resection. Scand J Gastroenterol 45: 1480-1487, 2010. 